\title{
Campylobacter Jejuni Infection
}

National Cancer Institute

\section{Source}

National Cancer Institute. Campylobacter Jejuni Infection. NCI Thesaurus. Code C43300.

An infection that is caused by Campylobacter jejuni. 